\title{
It's a bit inappropriate: What to avoid when using humor in teaching politics
}

\author{
Alexander P. Martin \\ Mediterranean Institute of Technology \\ South Mediterranean University \\ Les Jardins du Lac 2, 1053, Tunisia \\ alex.martin@medtech.tn \\ https://msb-online.academia.edu/AlexanderMartin \\ ORCID: 0000-0003-2364-5613
}

\begin{abstract}
While the benefits of using humor in teaching have been documented in the literature, this article undertakes qualitative research to examine its associated risks. This is not to discourage the use of humor as a pedagogical tool in the teaching of politics. Rather, through analysis of data from three focus groups of $2^{\text {nd }}$ and $3^{\text {rd }}$ year Politics and/or International Relations (Pol \& IR) students, this article advances a student-centric understanding of the pitfalls to be avoided by Pol \& IR lecturers seeking to harness the benefits of humor in their content delivery. The main findings are students expect professionalism from academic staff, therefore, the subjective understanding of what is appropriate or inappropriate makes the use of humor in teaching difficult to judge. The data highlights how a friendly and approachable, rather than a serious, lecture persona can help make humor attempts more palatable. Notably, serious, divisive, and personal topics are inappropriate themes for humor while the overuse of humor techniques has a detrimental pedagogical impact.
\end{abstract}

Keywords: Pedagogy, Education, Politics, Humor, Focus Group research.

\section{Introduction}

Although existing educational literature supports the extensive and unequivocal social and pedagogical potential of using humor in teaching, the research also consistently highlights the risks of this didactic approach, if poorly executed. It identifies what does not work; namely that offensive and prejudice-based humor, overly intellectual and unrelatable jokes, out of date cultural references, or irrelevant remarks are bound to fail. To further develop this cautionary literature, empirical findings from this study develop a nuanced and student-centered understanding of the numerous risks associated with lecturers making humor attempts. Overall, the focus group participants - 2nd and 3rd year Pol \& IR undergraduate students from the universities of Durham, London South Bank, Nottingham, and Swansea - appreciated lecturers making humor attempts. However, they also highlighted several issues with using humor in lectures and seminars, relating to timing, frequency, relatability, appropriateness, and potential to offend. In particular, the power imbalance and unfamiliarity of the student-lecturer relationship can make students feel vulnerable, which means that forms of banter or mockery, at students' expense, should be avoided.

This article contributes to literature on the pedagogical use of humor in teaching by using student-centric focus group data to corroborate and advance the existing literature on the drawbacks of using humor in teaching Pol \& IR. It addresses a methodological gap in the humor 
and teaching literature that relies on lecturers' perspectives or narrow positivist survey data that lacks personalized engagement with students. Student-participant focus groups enable undergraduate perspectives to be central to collective meaning-making of humor attempts from academics in higher education institutes.

This article discusses existing literature on the use of humor in teaching, juxtaposing the pedagogical benefits with the practical challenges and risks of including humor attempts in effective content delivery. The methodology section justifies the use of focus groups to highlight student perspectives and explains the ethical rationale behind using hypothetical scenarios to elicit discussion. The results section analyses risk themes from the focus group data and how they support and develop existing literature on the drawbacks of using humor in teaching. The final section briefly discusses the importance of enthusiasm and the use of relatable teaching examples as lower-risk alternatives to using humor. The conclusion merges the scenario-specific risks and verifications of the existing literature to produce an updated list of general risks for the use of humor in teaching Pol \& IR.

\section{The benefits of using Humor in teaching}

Existing literature on the effectiveness of using humor techniques in teaching across several different academic disciplines, such as studies on Statistics (Berk, 1996), Social Science and Physical Science, (Nesi, 2012) Psychology (Appleby, 2018), Physics (Worner et al., 2010), Chemistry (André, 2013) Medicine (Narula et al., 2011), Nursing (Englert, 2010), and English as a foreign language (Rafiee et al., 2010) demonstrate numerous benefits including increased student subject engagement and decreased stress, in addition to pedagogical benefits such as improved critical analysis skills. This is important, as critical analysis is a fundamental skill for students in social science, especially Pol \& IR.

Humor can be a highly effective educational tool that makes students' learning environment more comfortable and their learning experience more enjoyable. Using humor in teaching can, inter alia, facilitate comprehension (Garner, 2006) (Özdoğru \& McMorris, 2013) maintain student interest (Hellman, 2007), increase students' interest and retention (Shatz \& Helitzer, 2005), improve student perceptions of learning (Wanzer \& Frymier, 1999), motivate students (Goodboy et al., 2015) facilitate rapport (Granitz et al., 2009) and make lecturers more approachable (Appleby, 2018). Furthermore, as students are experiencing high levels of stress and anxiety ${ }^{1}$, using humor can relax the students (Kher et al., 1999) and "a wide range of lowrisk humor techniques can be very effective in reducing anxiety and improving learning and performance" (Berk, 1996, p. 88). Of course, using humor in content delivery does not address any of the underlying causes of stress or anxiety, but it can make the educational experience more enjoyable as students preferred instructors who used humor (Fortson \& Brown, 1998).

\footnotetext{
${ }^{1}$ A Uni Health study (https://unihealth.uk.com/reports/) noted that $80 \%$ of higher education students reported symptoms of stress or anxiety and NUS study noted $87 \%$ experience stress and $77 \%$ experience anxiety (http://appg-students.org.uk/wp-content/uploads/2016/03/Mental-Health-Poll-November-15-Summary.pdf). (from Georgina Lawton (2019) Why are students at university so stressed? The Guardian. Available at https://www.theguardian.com/education/2019/may/31/why-are-students-at-university-so-stressed
} 


\subsection{Humor in teaching politics}

If "political Humor is as old as politics" (Shally-Jensen et al., 2018, p. 30) then it could become part of the teaching of politics at university level. In particular, if humor is embedded as part of a critical pedagogy approach that uses humor in the teaching of politics to develop students' capacity to "question answers rather than merely answer questions" (Hayes, 2016, p. 254). Likewise, the inclusion of satire, the use of ridicule, irony or sarcasm to expose a vice or to lampoon an individual, has always been intimately related to politics as a form to criticize the powerful (Gonçalves, 2010). Therefore, encouraging the development of critical analysis skills can also enable students to highlight the absurd. "Humor sometimes manages to enhance commonsensical views on political affairs rather than promote radical thinking" (Tsakona \& Popa, 2011, p. 2) by highlighting the absurdity of the political actor's decisions or behaviors.

Beavers (2011) and Hayes (2016) both designed academic courses that embedded The Daily Show and their research demonstrates its positive pedagogical benefits. "Although The Daily Show isn't the most truthful political news show, it does make people think more about issues. Jon Stewart ${ }^{2}$ uses humor to point out unique angles of criticism, which essentially forces viewers to see different views, some of which would have otherwise been overlooked" (Beavers, 2011, pp. 418-419). Indeed, the show's format uses "satire and parody as a means of social and political critique" (Torosyan, 2007, p. 205) and MacMullan believes that intellectuals "study and emulate Jon Stewart if they want to be relevant to the public" ((MacMullan, 2007, p. 57). This begs the question; should Pol \& IR lecturers adopt political comedy to not only engage students but make them "think while they laugh"? (MacMullan, 2007, p. 58).

\section{Drawbacks of using humor in teaching}

Despite the potential pedagogical, student-lecturer relationship, and student experience advantages associated with using humor in teaching, the literature also tells a cautionary tale regarding the risks. At best, students may roll their eyes or groan, but humor attempts can have negative consequences, even if unintended. As this section argues, the location and the social conventions of a lecture or seminar make humor attempts more challenging. In addition, lecturers must ensure the students will 'get' the joke which may require educating before subverting with humor. Lecturers are also in a position of relative power to students, which can create a challenging dynamic for successful humor attempts.

\subsection{Humor attempts can have both unintended and negative consequences}

Comedians run the risk of their material being misunderstood or misinterpreted. Ricky Gervais identified that his work is taken out of context; "They think that every joke is a window to the comedian's soul - because I wrote it and performed it under my own name, that that's really me. And that's just not true." 3 This may be due to the irony, sarcasm, or satire being lost on the audience, the audience not realizing that the comedians are adopting a provocative persona;

\footnotetext{
2 Host of Comedy Central's The Daily Show from 1999 to 2015.

${ }^{3}$ Michallon, Clémence (2020) Ricky Gervais says people are mistaken about his humour. Independent. https://www.independent.co.uk/arts-entertainment/comedy/news/ricky-gervais-golden-globes-jokesinterview-a9481071.html
} 
such as Bill Burr or Anthony Jeselnik ${ }^{4}$, or that comedians' approach to addressing contentious issues can offend, such as Dave Chappelle's Netflix specials(Gillota, 2019). Lecturers must also tread carefully when making humor attempts because "the reception of any jokes cannot be definitively controlled by the comic" (Krefting, 2018, p. 252).

While Powell \& Andresen (1985) highlight positive aspects of using humor in teaching, their article also addresses the negative outcomes of teachers making humor attempts such as causing offence or alienation. Selecting appropriate comedic examples is important as "careless choice of illustrative or anecdotal material might convey the impression that the teacher holds, say, sexist or racist views or is perpetuating an undesirable image of a particular group" (Powell \& Andresen, 1985, p. 82). In addition, relying on humor as a principal method of delivery could undermine the academic's credibility as they may be perceived as "clownish rather than appropriately amusing" (Powell \& Andresen, 1985, p. 84). Empirical focus group findings in this research seek to understand what students find appropriate or would tolerate from their lecturers.

\subsection{Social conventions are often defined by location.}

The risk of humor attempts being misunderstood is also raised by the location in which the joke is made. Lecturers making attempts at using humor are hindered by the social conventions or expectations of a lecture theatre, seminar room, or online teaching environment. These are not expected to be locations of comedic interaction. "An audience, especially one in a comedy club or at a live television or radio show, comes to the performance voluntarily and is primed to laugh" (Shally-Jensen et al., 2018, p. 535). This is not the case in a lecture or seminar where attendance is voluntary but participants are not primed to laugh. Daniel Audritt ${ }^{5}$, a professional stand-up comedian and writer, notes that location is an important factor in whether or not a humor attempt will succeed or fail;

"I think with a comedy club there is at least an understanding that you might hear something you don't like or agree with. But with a lecture, you're saying a joke in an environment that's not got those parameters set out. For example, a joke about cancer is dark (humor) in a club, but really inappropriate in a hospital. I think the environment gives an understanding of the rules" (D. Audritt, personal communication, 2020).

Although "people laugh far more often in groups than when alone" (Morreall, 2005, p. 67), should lecturers elect to use humor in their content delivery or establish a "funny lecturer" persona (Tait et al., 2015), to establish this as a convention, they should do so consistently. This may require lecturers to use humor from the beginning of the course, to make students 'used to' humor or expect it in lectures and seminars, rather than introducing humor techniques midway through the semester.

\footnotetext{
${ }^{4}$ Sims, David (2019) Bill Burr Knows Better. The Atlantic. Available at https://www.theatlantic.com/entertainment/archive/2019/09/bill-burr-cancel-culture/598669/

${ }^{5}$ Interview conducted by the author. https://www.danielaudritt.com/
} 


\subsection{Educating needs to come before subverting with humor.}

A key risk of using humor in politics, or any subject, is students not 'getting' the joke. Appleby's quantitative survey research provides student responses to lecturers making jokes that were too advanced or too niche for students' levels. The results note cases of lecturers' "failure to understand students' level of understanding of the information being taught" and citing examples such as;

○ "In math, when the instructor told a joke that only math majors would know — it was not funny".

○ "My chemistry instructor would try to use chemistry jokes that none of us could understand."

- "My math professor was telling us a joke, an intellectual joke, and none of us understood." (Appleby, 2018)

Comedians understand the importance of knowing their audience to gauge how they will react to their material. "Your material might be great but not right for a particular audience. Your material might be hip but your audience might be from Omaha" (Carter, 1989, p. 133). To avoid the risk of "bombing"? , Audritt tries to learn what he can about his audience and adjusts his material accordingly. "I'd always read the room based on how they [the audience in the comedy club] reacted to an earlier joke or another comic to give myself the best chance of playing the room well" (D. Audritt, personal communication, 2020). Therefore, just as lecturers use course-appropriate academic material, they must also adjust their humor material to the level of their audience.

The delivery of comedic material requires the 'setup' before the 'punchline', and students also need sufficient subject understanding to understand the joke. Political humor, of course, requires some political knowledge, meaning it "cannot be understood by people who are not informed on political issues" (Tsakona \& Popa, 2011, p. 8). Beavers emphasizes that "instructors who use such comedy must provide students with the tools they need to "get" the jokes and appreciate the humor while keeping the overarching objective of building criticalthinking skills firmly in mind" (Beavers, 2011, p. 417). It is therefore fundamental that students understand the "reality" and have sufficient a priori subject understanding before they can mock it and find the "subversion" amusing and memorable. Therefore, humor attempts must be well planned because lecturers must know their 'audience'. The focus groups in this research support this process and help prevent lecturers from failing in their humor attempts.

The responses to the only open-ended question in Appleby's survey (2018) "Please give an example of a situation in which one of your instructors tried to use humor in the classroom, but was unsuccessful, and how this failure affected you" highlights the potential pitfalls for lecturers considering using humor. Appleby sub-categorized these "Failed attempts at humor" as

- Failure to understand students' level of understanding of the information being taught

\footnotetext{
${ }^{6}$ Carter is using Omaha, the largest city in Nebraska, USA, as code for people with traditional or conservative views.

7 When a comedian has failed to get an intended laugh. Dean, Greg (2000). Step by Step to Stand-up Comedy. Portsmouth, NH: Heinemann. p. 190.
} 
- Offensive, rude or sarcastic humor

- Trying too hard to be funny

- Jokes about particular students

- Humor that is unrelated to the subject matter of the class

- Humor that is out-of-date

- Laughing at own jokes

- Humor that backfires

\subsection{Lecturers are in a position of relative power to students.}

Meyer calls humor's ability to both unite and divide makes it a paradox (Meyer, 2000, p. 323). Using divisive humor, such as teasing or making jokes about a particular student, is the riskiest tactic that requires considerable social capital and rapport with students to be effective. Likewise, the "darker side of humor" where teachers potentially misuse their status and power to humiliate, belittle or put-down others, obviously can "have a very negative impact on students and on their approach to learning” (Powell \& Andresen, 1985, p. 83).

Lecturer-centric research does not account for impact of this power imbalance. Hellman believes that you can occasionally "verbally abuse" students and certain students will "volunteer to be the target of these darts" (Hellman, 2007, p. 37). Interview data collected by Tait et al. shows that "interviewees [academics] generally stated a willingness to tease their students; however, only when they had reached a point in the pedagogic relationship when it was obvious that the mockery is relatively benign, and where trust had developed" (Tait et al., 2015, p. 10). Tait and Hellman do not, however, capture the perspectives of students who perhaps do not appreciate being teased. Appleby's survey collects students' opinions but, with the exception of one question, consists of close-ended questions and does not effectively illuminate the power dynamics of the student-lecturer relationship.

\section{Research Design}

This research conducted three focus groups to collect in-depth and nuanced student-centered data from $212^{\text {nd }}$ and $3^{\text {rd }}$ year undergraduate Pol \& IR students. Focus groups comprehensively elicit individuals' views but also capture the collective understanding of suitable and effective humor techniques through participants' interactions. This is a departure from the existing literature on the use of humor techniques that relies on lecturers' perspectives, data from qualitative interviews or narrow positivist survey data that lacks personalized engagement with students (Berk, 1996). The focus group method redresses this imbalance by enabling unobstructed discussion that places the undergraduate student participants as central to the collective meaning-making of humor.

Focus groups participants were presented with six imaginary scenarios (see appendix), where lecturers make "humor attempts" in their lecture and seminar situations. These hypothetical scenarios were designed from issues raised in the existing teaching and humor literature and mentioned in the discussion of findings section. These aimed to:

- Understand how lecturers can avoid making unsuccessful humor attempts; 
- Understand what students consider appropriate and inappropriate humor attempts;

- Understand how the academic-student power dynamics impact the humor delivery;

- Understand the importance of lecturer persona in humor attempt delivery.

After the six scenarios were discussed, the participants were encouraged to openly discuss their views regarding the use of humor in teaching and share any positive or negative personal experiences of lecturers using humor.

The use of hypothetical scenarios mitigated the potential risk associated with the unequal power relationship between the primary investigator (a lecturer) and students as students may have been reluctant to directly criticize other academics. The hypothetical scenarios sought to redress this imbalance and effectively capture an accurate representation of students' perspectives and experiences. To ensure confidentially, focus groups transcripts are anonymized, students have aliases, and any lecturers mentioned by name have been anonymized. A trigger warning was included so that participants would notify each other if they were going to cite an example of a humor attempt that may be considered offensive.

Focus groups varied between four and nine participants since a group of more than 10 participants is difficult to moderate and limits "each person's opportunity to share insights and observations" (Krueger \& Casey, 2015, p. 68). I aimed to have gender-balanced focus groups to reflect the almost equal number of male and female students registered in politics courses for the 2018/19 academic year. ${ }^{8}$ However, as recruiting equal numbers of male students was not possible, the focus group data over-represents female participants 2:1 (7 male and 14 female). Due to Covid-19 social distancing restrictions, focus groups were conducted on Zoom and lasted between 60-90 minutes.

The data analysis process used thematic coding for systematic content analysis. This positioned the group as the unit of analysis that effectively summarizes findings. Collected data was coded into "Benefits" and "Risks" categories, which were then divided into focus group specific inductive themes. This article focuses on the negative findings associated with the lecturer's humor attempt. In addition, ethnographic data analysis of individual quotes provides further detail to the risk themes. This two-level data analysis process ensures the findings are presented differently to interview data, which ensures that "the 'spirit' of the group" is not ignored, but it also guarantees the "specific context within which the material was generated" is not missed either (Wilkinson, 1998, p. 196).

\footnotetext{
${ }^{8}$ Based data from HEIDI Plus: HESA Student Full Time Equivalent (FTE) v1 https://www.hesa.ac.uk/services/heidi-plus and HEIDI Plus: HESA Student Full Person Equivalent (FPE) v1 datasets https://www.jisc.ac.uk/heidi-plus\#, for the 2018/19 academic year, 33,230 males and 34,025 females are enrolled on Politics and International Relations courses.
} 


\section{Results}

\subsection{Focus Group data}

This section firstly analyses the focus group findings from each scenario and secondly analyses how the focus group data corroborates and advances the existing literature on the drawbacks of using humor in teaching.

\begin{tabular}{|l|l|l|}
\hline Scenario 1 context & Literature used to inspire scenario design & Risks \\
\hline $\begin{array}{l}\text { At the beginning of } \\
\text { the lecture, }\end{array}$ & $\begin{array}{l}\text { "Rule 1: Whatever it takes, get their } \\
\text { attention." (Davis \& Arend, 2013, pp. 78- }\end{array}$ & $\begin{array}{l}\text { Time-consuming, } \\
\text { inappropriate, }\end{array}$ \\
the lecturer tells a joke & $\begin{array}{l}\text { 79). Work harder to better engage your } \\
\text { that is unrelated to the } \\
\text { content of the lecture. }\end{array}$ & $\begin{array}{l}\text { students (Hammer et al., 2010). "Modern } \\
\text { students have a shorter attention span than } \\
\text { their predecessors, and expect to be } \\
\text { entertained" (Johnson, 2018). }\end{array}$ \\
\hline
\end{tabular}

Participants in all Focus Groups (FGs) recognized that a joke at the start of a lecture could be an effective ice-breaker or warm-up that could also make students perceive the lecturer as friendly and approachable. However, three key risks with this humor attempt were identified. Firstly, participants identified that they would not appreciate jokes that take too long and are at the expense of lecture content. Jenny, from Focus Group 2 (FG2), thought "if it takes a long time, then maybe it will be a problem because that will eat into the lecture time". Amy and Emma (FG2) concurred;

Amy: "If the lecturer starts a 45-minute lecture with a five-minute joke, if I was a third year or a second year who is rushing on my essays, I would think that you might be a bit too pretentious and trying to be too friendly and that you're trying a bit too hard because some of us just want you to get on with the lecture."

Emma: "I agree. If lecturers take a long time to start, I always think "what are you doing? Can we just do what we're here for? "If it takes a long time, its wasting everyone's time a bit"

Secondly, it can seem like the lecturer is trying too hard. Amy's point about students perceiving lecturers who tell jokes to be trying too hard was echoed by Sarah (FG2); "if you're trying too hard to appear friendly with the students, it can come across quite bizarre”. Amy (FG2) agreed with Sarah about academic staff being over-friendly and recounted a personal experience; "when he (the lecturer) tried to get a bit personal and asked us personal questions, we found it very bizarre and we got a bit creeped out by his interactions with us". Lecturers using humor to ingratiate themselves with students was also mentioned by John (FG3); "I've had lecturers that try to make jokes, but they end up being a little bit too much, like they're trying too hard."

Thirdly, the appropriateness of the joke was identified as potentially problematic. Participants in different focus groups raised the same point. "If the joke is too personal or inappropriate, it might make the atmosphere worse." (Frederick FG2) and "as long as it's not an inappropriate joke." (Zara FG1). Appropriateness can both relate to how well the lecturer knows the students and if the joke is course or lecture subject relevant. While other participants did not think an 
"ice-breaker" joke had to be related to the lecture content, international students, who accounted for $23.66 \%$ of all UK higher education enrolments in $2020^{9}$, may see this differently. As Carter (1989) and Audritt (2020) identified the importance of knowing your audience and adjusting your material accordingly, Jenny highlighted the perspective of an international student.

Primary investigator: "if the joke was related (to the lecture), would that make it more acceptable?"

Jenny: "I think it would because one problem I have with jokes is that if I don't understand it, especially if it's a reference to Western culture, because I'm not from the UK. And if I don't understand that, I can sometimes feel excluded from the conversation. And that's quite bad. But if it is related to the content of the lecture, then presumably, I should have done the reading. And I should have understood what the joke is. So that can make me feel a bit better."

Thus, even a seemingly harmless joke has the potential to alienate some students (Powell \& Andresen, 1985).

\begin{tabular}{|c|c|c|}
\hline Scenario 2 context & Literature used to inspire scenario design & Risks \\
\hline $\begin{array}{l}\text { In a seminar, a } \\
\text { student asks the } \\
\text { lecturer a question. } \\
\text { The lecturer's } \\
\text { response is relevant } \\
\text { and humorous but } \\
\text { targets the student } \\
\text { with } \\
\text { mockery/banter. }\end{array}$ & $\begin{array}{l}\text { "interviewees generally stated a willingness to tease } \\
\text { their students; however, only when they had } \\
\text { reached a point in the pedagogic relationship when } \\
\text { it was obvious that the mockery is relatively benign, } \\
\text { and where trust had developed" (Tait et al., 2015, p. } \\
\text { 10). Teachers using their status and power to } \\
\text { humiliate, belittle or put-down others "can have a } \\
\text { very negative impact on students and on their } \\
\text { approach to learning" (Powell \& Andresen, 1985, p. } \\
\text { 83). }\end{array}$ & $\begin{array}{l}\text { Inappropriate } \\
\text { and } \\
\text { demotivational }\end{array}$ \\
\hline
\end{tabular}

Although Tait et al. identified some lecturers enjoyed engaging in "relatively benign" mockery with their students if sufficient "trust had developed" (2015:10), focus group participants saw negative consequences of this humor attempt, citing it as demotivational and inappropriate. Participants discussed how it would harm their learning experience, notably if the teasing occurred in response to a student asking a question and especially if the jokes are about students not knowing things they are not expected to know;

- 'I'd have a really sour taste about that. Because you take an opportunity to insult me when I'm putting myself out there and being vulnerable. So I wouldn't take it well at all." (Kelly FG2)

- "I just don't think it's okay, in any situation. They are in a learning environment, you can't just mock people that are trying to learn if they're making an effort." (Emma FG2)

\footnotetext{
${ }^{9}$ ICEF Monitor (2021) Foreign enrolment in UK higher education reached a new high in 2019/20. Available at https://monitor.icef.com/2021/01/foreign-enrolment-in-uk-higher-education-reached-a-new-high-in-2019-20/
} 
- "It would make me feel that I'll just not ask anything next time if I knew that they would respond this way." (Jenny FG2)

- "There's no advantage to mocking or ridiculing someone who is probably just asking a question to benefit their own knowledge." (Sarah FG2)

- "I think students are usually vulnerable when asking a question because it's admitting that they don't know. And to receive banter in return, can be a pushback for the student, or it can actually be hurtful." (Eve FG1)

- 'I think it's easier as a blanket rule, just to say it's a bit inappropriate because you don't know the student well enough, most of the time, to interact with them on a level that they are comfortable with... Everyone remembers the time that they were mocked, I'd say that at least $70 \%$ of us has mentioned a time that they were and we all remember it. And none of us really said it with a good connotation to it, so obviously, it's not that accepted" (James FG2)

Individual responses, as well as group interactions, demonstrated that students did not view humor attempts made at their expensive favorably:

Laura (FG3): "I think that's very negative because as students, we're all here trying to learn and it takes so much courage to speak in a seminar. So when you get that mockery response, it kind of discourages you from speaking again in the seminar.

Victoria (FG3): "Yeah, I would second that. I think it's entirely inappropriate, and it's not professional. And because you will have students who sit in that seminar who are too scared to ask a question, and they see that kind of response. And I think it's a reinforcement for them not to ask any questions."

Participants expanded on why the power dynamics of the student-lecturer relationship makes banter or mockery unsuitable. The major caveats regarding student-lecturer joking is that it is acceptable when sufficient rapport and trust is developed (Tait et al. 2015) or that a lecturer with a consistently friendly persona, who regularly makes jokes, and has set a particular "tone" or convention for the course could make such comments without upsetting students, as FG2 participants noted.

David: "I had Dr (blank). He makes so many jokes. And says things that could be a bit unacceptable if he wasn't a lecturer, I mean the political things he implies, but he's funny."

Amy: "I also had Dr (blank) as my lecturer. I think it was more about the style he teaches in. I would be fine when he mocks me about something that I got wrong because of the tone that he set for the entire module. So the tone was very important. So like, if he didn't start off with making very, very crude jokes about historical figures in the lectures, then if in the seminars he mocked me with humor when I ask a question, then that would be unacceptable for me."

Primary investigator: "Okay, so you're saying that if they set the tone from the beginning, where everybody is fair game, then it's acceptable?"

Amy: "Yeah, yeah"

Emma: "I'm taking one module this year, my seminar leader, we call her by her first name, she constantly makes jokes against herself, against political figures, and against people who 
she knows within the group who can take it. But she's built that rapport with us. So I definitely think that the tone that the person sets consistently reflects the appropriateness of using humor, not even mocking people, but just like saying things that are just very light hearted."

However, FG3 participants identify how, irrespective of established rapport, these exchanges could negatively impact other students. Just as "the reception of any jokes cannot be definitively controlled by the comic" (Krefting, 2018: 252), lecturers cannot be sure how other students would interpret the banter or jokes made with the students who can 'take it'.

Victoria: "In my opinion, the student-lecturer relationship is not necessarily strong enough to make a humorous comment like that and for it to land the way they expect. It may work in an individual circumstance, if my dissertation supervisor is also my seminar leader, and he can make that joke with me because we have a good relationship. However, he can't account for how a student who doesn't know us might take that and how they might feel about then asking questions themselves."

John: "If your dissertation supervisor makes a joke and you're both laughing about it, that's alright."

Victoria: "Yeah, obviously, for me, it's fine. But if someone else is in the class, who's quite nervous about asking a question, or maybe doesn't understand and is nervous to ask, they might worry that they'll have a joke made about them. Just because I receive it well doesn't mean that someone else might necessarily receive it well. And I don't think a lecturer is always well placed to judge that."

\begin{tabular}{|l|l|l|}
\hline Scenario 3 & Literature used to inspire scenario design & Risk \\
\hline A lecturer uses a & "Memes work better. Since they come with a preloaded & Overuse \\
relevant and & meaning, they tick the shared common ground box. They & \\
humorous meme & can even be educational" (Tregoning, 2018). & \\
or cartoon to & $\begin{array}{l}\text { Memes are "very quickly and easily produced and } \\
\text { illustrate the point } \\
\text { being made. }\end{array}$ & $\begin{array}{l}\text { individuals to offer their (humorous or not) creative } \\
\text { perceptions and comments on current (political or other) } \\
\text { events (Avidar 2012)" (Tsakona \& Popa, 2013, p. 2). }\end{array}$ \\
\hline
\end{tabular}

Participants thought that memes can be an effective teaching tool if used sparingly. The overuse of memes negatively impacts both the content delivery and the perception of the lecturer. FG2 and FG1 participants thought too many memes would diminish the seriousness of the module.

- "Every slide had one. And it was funny. And it did initially help to remember the information, but I also found that I took the module a little less seriously, just because every time I was looking at a slide, it was a joke" (James FG2)

- "Putting a joke in every single slide? That creates the whole perspective of the module that it's not very serious and I don't have to be serious" (Jenny FG2) 
- "If at the same time you put five memes in a row, the students will probably think this is a bit over the top. So it depends on the quality as well as the quantity of memes that you put in a slide." (Eve FG1)

- "It's definitely good to include a meme, but not go overboard with it.... Overboard would be including several throughout one lecture or basing the lecture around having little jokes here and there, rather than focusing on the actual content." (Anika FG1)

Also, the overuse of memes could change students' perception of the lecturer.

- "the lecturer doesn't want to become that stereotypical "alternative" high school teacher that uses memes and tries to be cool and young because it becomes a bit corny and it just loses your attention. And I guess, to an extent, the respect of the class." (John FG3)

\begin{tabular}{|l|l|l|}
\hline Scenario 4 & Literature used to inspire scenario design & Risk \\
\hline A lecturer uses a & 'Humor that is out-of-date' as a failed humour & $\begin{array}{l}\text { Overuse, } \\
\text { pop culture } \\
\text { reference as an } \\
\text { analogy or } \\
\text { comparison to } \\
\text { explain a concept. and } \\
\text { excluding }\end{array}$ \\
& $\begin{array}{l}\text { "I always look for humorous sorts of things to } \\
\text { exemplify points that I'm making, whether it be from } \\
\text { the Simpsons, or other forms of popular culture" } \\
\text { (Tait et al., 2015, p. 11). } \\
\text { "cartoons of suitable type (e.g. visual puns') can be } \\
\text { used with the intention of serving a direct teaching } \\
\text { function such as facilitating the learning of } \\
\text { definitions and symbols and promoting insights into } \\
\text { difficult concepts." (Powell \& Andresen, 1985, p. 87) }\end{array}$ & \\
\hline
\end{tabular}

Participants noted that pop culture references have value in helping explain complex ideas or concepts and helping students remember content. However, "not everyone follows pop culture" (Ryan FG1) and the reference "might not necessarily work if it's an obscure show" (John FG3). Also, like memes, participants were skeptical about the overuse of pop culture references.

- "I think too many pop culture references would lower the quality of the teaching... you should be a bit funny and put a level of familiarity when you teach, but not too much." (David FG2)

Laura (FG3): "Pop culture examples could be overused. And especially that not everyone relates to those references. So, you're going to use "beer" this time, next time try using something else, like football, or Game of Thrones. It's of subjective interest to students."

Natalie (FG3): "I agree with you (Laura). If it's overdone and the analogy is used throughout the whole module, and you don't understand that, it would be less engaging."

Victoria (FG3): "I think if it's overused, it draws attention away from what you're trying to teach. I mean, I don't know anything about football, so if it went on and on I would feel quite bored and kind of unengaged with that." 
Participants noted that irrelevant comparisons to pop culture are unhelpful pedagogical tools.

- "some are fine, like when it's actually something relevant and that can be a good analogy, but sometimes it will be completely off topic." (Emma FG2)

- "But not just something grabbed from an episode of the Simpsons that has nothing to do with what has been taught." (Eve FG1)

The most problematic application of pop culture analogies is how they could be exclusionary for some students.

- "I don't get a lot of these references and I just kind of feel excluded from the conversation." (Jenny FG2)

- "I would completely agree with Jenny. Because I'm international as well and a lot of pop culture references that are English subject go over my head as well" (Angela FG2)

In response to Jenny and Angela's concerns about pop culture being exclusionary, James (FG2) argued that "if you're going to mention it, then you have the responsibility of explaining yourself. But, if it's worth mentioning, I don't think it's something that lecturers should shy away from." However, John (FG3) was not convinced that analogies are effective use of lecture time.

"Spend like 10 or 20 seconds on it. So if there are people who don't know or understand that series, musician, whatever, then it doesn't matter, because it's only 10 or 20 seconds. But some lecturers base a quarter of the lecture on that analogy. And then those people who are not aware of it are probably even more lost than when they came into the lecture."

This leaves lecturers who want to use a pop culture analogy to explain a complex idea with a dilemma. When I use a pop culture analogy, do I fully explain its relevance to the teaching point I'm making because I have to assume not all students will understand it, or do I make a quick comparison and move on? The former may bore the students who have no interest in this pop culture element while the latter may leave the students who do not understand it more confused than before.

\begin{tabular}{|c|c|c|}
\hline Scenario 5 & Literature used to inspire scenario design & Risk \\
\hline $\begin{array}{l}\text { A lecturer delivers } \\
\text { an informative and } \\
\text { well-researched } \\
\text { lecture that } \\
\text { highlights key issues } \\
\text { but supports the } \\
\text { content with silly or } \\
\text { comedic analysis, } \\
\text { absurd analogies or } \\
\text { comparisons that } \\
\text { makes light of } \\
\text { serious topics. }\end{array}$ & $\begin{array}{l}\text { "Jon Stewart uses humor to point out unique angles of } \\
\text { criticism, which essentially forces viewers to see } \\
\text { different views, some of which would have otherwise } \\
\text { been overlooked" (Beavers, 2011: 418-419). } \\
\text { Use of absurdity to develop critical thinking } \\
\text { (Torosyan, 2007, p. 114). "In presenting politics as the } \\
\text { theatre of the absurd, Stewart seemingly simplifies it." } \\
\text { (Baumgartner \& Morris, 2006, p. 362). Satirical } \\
\text { comedians can use "their satirical craft as a method of } \\
\text { critical inquiry" and they "use their art to address } \\
\text { societal norms, mores, and injustices" and "expose } \\
\text { society's inequities" (Hayes, 2016, p. 256). }\end{array}$ & $\begin{array}{l}\text { Overuse, } \\
\text { irrelevance, } \\
\text { and } \\
\text { exclusionary }\end{array}$ \\
\hline
\end{tabular}


In relation to both the global popularity and the critical political analysis programs like The Daily Show, this scenario was designed to explore the use of satire in teaching politics at university level as part of a critical pedagogy approach. Participants, however, thought that, for a lecture or seminar setting, this humor attempt could be too silly and inappropriate for serious topics. The absurd analogy example used was an image from the Last Week Tonight with John Oliver to highlight the self-inflicted economic damage that the UK leaving the European Union would cause. He said, "Brexit is basically Pompeii if the citizens voted for the Volcano"10. Although this appealed to some participants, some considered this humor attempt too silly.

- "I think putting this up on the presentation, and I see that I think that's a bit much and it looks a bit amateur." (Kelly FG2)

- "It feels like a distraction on the slide. Especially if I don't understand it, I will spend a lot of time trying to figure it out. And rather than listening to what she has to say that was more important." (Jenny FG2)

- "It could be because it's not my sense of humor. But to me, this is embarrassing" (Victoria FG3)

- "I think this sort of humor is quite subjective" (Anika FG1)

Participants also noted that this could be divisive.

- "If someone supported Brexit, they could find it inappropriate. And they may mind the silliness that comes with the joke." (Anika FG1)

- "If somebody felt offended by this because they voted Brexit, that could make them not like the lecturer." (Zara FG1)

David highlighted that using 'silly' humor on divisive subjects can reinforce cleavages. He noted that "those who think it's really like they voted for the volcano" would like the joke, but pro-Brexit students would not appreciate it. David also drew on his experience and recalled when a lecturer

"was talking about the 2003 war in Iraq, and made a joke that laughed at Britain...something about Britain joining the US and every policeman needs a dog... And all the foreigners understood and they laughed and the British people in the room, they didn't understand... he just reinforced the fact that some laugh about this and the others didn't understand it",

Participants believed that joking about serious issues is inappropriate. Genocide and suicide were amongst the several examples of unfitting comedy subjects.

- "for something like the war in Iraq or Palestine issue, I don't really feel like you can make light of those situations" (Ben FG3)

- "When you're trying to make light of a serious topic, the delivery of it in terms of it being silly or not isn't what matters, what matters is making light of a serious topic, it's a very fine line to tread" (Victoria FG3)

\footnotetext{
${ }^{10}$ Last Week Tonight with John Oliver (2019) Brexit III. HBO. ff. 0:14:30. Available at https://www.youtube.com/watch?v=aBQfSAVt0s\&t=870
} 
- "Not every serious issue is related to a meme or a joke." (Laura FG3)

\begin{tabular}{|l|l|l|}
\hline Scenario 6 & Literature used to inspire scenario design & Risk \\
\hline A lecturer delivers & "self-deprecation serves to signal modesty and & Awkward, \\
informative and well- & approachability" (Nesi, 2012, p. 87). \\
researched lectures but & "used by almost all the interviewees, and had the \\
does not take & advantage of appealing to those who, while \\
himself/herself too & enjoying and valuing laughter themselves, lacked \\
seriously and uses self- & confidence in their own ability to make students \\
deprecation to poke fun & laugh" (Tait et al., 2015, p. 11). & \\
at themselves. & & \\
\hline
\end{tabular}

Participants agreed that if lecturers occasionally make self-deprecating jokes, it can redress the power imbalance and create a relaxed learning environment. However, this humor attempt can also leave students feeling confused and awkward, especially if the self-deprecation related to lecturer's appearance, personal life, or mental state.

Sarah (FG2): "if they sound like they're feeling sorry for themselves, it makes you feel a bit awkward, and how do you respond to that?... should I be saying the opposite to make them feel better?"

Angela (FG2): "Yeah, sometimes lecturers say sad things, and you just end up a bit concerned for them rather than finding it funny."

Jenny (FG2) added to these comments and recalled a lecturer who compared something collapsing to his ongoing divorce; "And he said it with a smile and wanted all of us to laugh and we all were just like "do you want us to comment?". Emma (FG2) also thought that "if it gets too personal or too dark, then that's the point where you're like "what's going on? Are you okay?". Participants in FG1 and 3 also expressed concern about overly personal selfdeprecation making students feel awkward.

- "She was quite a big lady and she made fun of her weight. And I thought it was a bit much. I felt a bit uncomfortable because you don't know how to respond to that. So, I think that's inappropriate." (Zara FG1)

- "if they're making fun of perhaps their mental health or them getting down, that might affect other students that are facing similar issues. " (Ben FG3)

Participants also considered self-deprecation as an indicator of lecturers lacking confidence which undermines their authority. Notably, Ryan (FG1) expressed that students could lose respect for "a lecturer that keeps making self-deprecating jokes."

- "If someone's making too much fun of themselves, it comes across like they don't have much confidence. So how am I meant to react? How much do I trust that you trust yourself to give me this lecture when you don't appear to trust yourself? There is a fine line between it being funny and thinking "are you okay?" (Courtney FG2) 
- "of course, it's all in jest, but I think them making jokes about themselves is undermining themselves and not really taking themselves seriously. I think it would have an impact on students' learning and also their ability to take the lecturer seriously." (Anika FG1)

\subsection{Enthusiasm and relatability: alternatives to the use humor}

The focus groups also produced data on the successful delivery of Pol \& IR course content without the use of humor. Firstly, passion and enthusiasm for teaching were considered just as, if not more, important than use of humor. John (FG3) noted that "some other lecturers don't make jokes but you feel like they really care about what they're teaching. They're passionate about it. So I think that's important as well." This led FG3 to discuss an entertaining and eccentric lecturer they all knew. "I think he was quite experienced and very passionate about teaching. So I think it really came through" (Victoria FG3). FG3 collectively decided that enthusiasm for teaching is more important than lecturers being funny. This was particularly pertinent because they thought trying too hard to be funny was detrimental.

An additional point about the importance of enthusiasm over humor was mentioned by FG2 participants who agreed that lecturers should avoid humor attempts that discourage students, especially on what Kher et al. (1999) refer to as 'dread courses'.

Frederick: "I don't know what's wrong with statistics, but they often try to make jokes that statistics is somehow boring or uninteresting, and so on. And it's really weird because you try to engage with the subject and a lecturer is trying to make jokes. But it's not making it better. It's making it worse."

Angela: "Yeah. I can really agree with that. A lot of times, lecturers know that something is kind of boring. So they say it, but I feel like that actually just does the opposite of what they're trying to do. Yeah, it would be more fun if they try to look for the fun, even in that boring thing. Because everyone's already thinking it's boring."

Kelly: "Yeah, part of my research projects module last year, we did a lot of statistical workshops and stuff like that. And the whole atmosphere of the room was just so dead, because we all knew the lecturer presented it to be this thing that we just have to do. And we have to know. And they tried to use humor to say like 'Come on, guys. This is really shit but we still have to do it'. That doesn't help us."

James: "Every lecturer I've ever had is like, this is going to suck, let's do it together. I mean it doesn't have to, or I mean, if you're going to start like that then, yeah, it's going to suck."

Thus, referring to quantitative political science methods as "sadistics" or making jokes like "if I had only one day left to live, I would live it in my statistics class: it would seem so much longer" (Friedman et al., 2002, p. 2) are demotivational and should be avoided.

Secondly, some participants thought that relatable examples or analogies could be just as pedagogically effective as humor based ones. Sarah and Kelly (FG2) discussed how the roleplay of "ordering a pizza with your housemates" was a highly effective tool, that was not humor focused, for applying political psychology concepts. 
Sarah: "the priming and framing of how decision-makers often make and present decisions, and how you can influence and who you're presenting it to. And then the lecturer used the example of when your housemates want to order a pizza. But then no one else wants to order a pizza. So how do you present it in the way that you'll get the desired outcome of ordering the pizza? We spoke about this for about 20 minutes in seminar groups, and obviously it's completely ridiculous, but it also was really beneficial because we applied it to how that is in real life in actual decisions, like it was the exact same concept behind the decision making and framing but obviously, just completely different scenarios."

Kelly: "We're learning about things like game theory, and framing and priming. It's so effective when they dumbed it down and present a really simple thing. And it's so relatable and it occurs so much in your life. And it may be a bit silly and a bit funny, but it makes it so much easier to understand. And I think she's really effective, our lecturer, in doing that. That's partly why I like really enjoy her classes"

\section{Discussion}

A comparison of the focus group data and literature review findings demonstrate that the focus group data corroborates and advances the literature review findings identified in sections 2.1 to 2.4 .

Regarding the unintended and negative consequences of humor attempts, firstly, a lecturer joking with a student, even if a good rapport exists between them, can unintentionally impact other students in the group. Secondly, Scenario 5 showed that a lecturer, by mocking one side of a serious or contentious issue (case study example Brexit) may cause or reinforce division and cleavages within a group, thus "what will amuse some people may offend or alienate others" (Powell \& Andresen, 1985, p. 82). Thirdly, humor attempts that use popular or cultural references may alienate students, in particular international students, if the reference is insufficiently explained. Finally, building on Appleby's survey (2018), which sub-categorized "trying too hard to be funny" under "failed attempts at humor", data from Scenarios 1 and 3 noted students did not appreciate and could lose respect for lecturers who try too hard (to be funny or friendly), even if this was unintentional. The delivery needs to seem somewhat natural or effortless and laughing at your own joke is uncool.

Participants confirmed that social conventions are defined by location. If lecturers adopt a friendly and approachable persona, build sufficient social capital with students, and establish a precedent for using humor in their teaching, it can help jokes land. Natalie (FG3) thought that if "you've got a serious lecturer, and then out of the blue starts taking the mick out of you", yeah, I think I'd be like "Okay, this is a bit odd, I'm a bit offended here". However, even if an excellent rapport is established, there are limitations on what can be considered acceptable in a higher education institute. As Audritt (2020) noted a joke about cancer could be funny in a comedy club but would be unacceptable in a hospital, this indicates lecturers' humor attempts need to be appropriate for lecture/seminar locations. Findings from Scenario 5 suggest that,

\footnotetext{
${ }^{11}$ British slang for mocking or teasing.
} 
without suitable explanation and framing, satire may be an ineffective humor tool and controversial and divisive subjects should be avoided. Likewise, a comedian could routinely make awkward and overly personal self-deprecation remarks but Scenario 6 findings indicated this is less acceptable from an academic in an educational setting.

Findings on the timing and level of humor attempts reinforce the need for educating before subverting with humor. Firstly, scenarios 3, 4 and 5 enabled participants to discuss the timing of humor attempts. Many noted that humor attempts can be effective breaks or segue to another part of the lecture, but also deploying them after key lecture content is more effective.

- 'give a meme after they've explained that point, now the students understand the meme. So whenever they read it, they might laugh at it, because at least they understand that part" (Ryan FG1)

- "And then at the end of it (a complicated subject), the joke is just like trying to relax for a little bit." (Eve FG1)"

- "I always think it's best at the end of a lecture to leave on. You're leaving with a bit of an analogy to draw on." (James FG2)

- "When memes and cartoons are used in lectures ... it often summarizes a point quite well.” (Courtney FG3)

Secondly, one participant raised the issue of lecturers making jokes that would not be widely understood by undergraduates, thus corroborating Appleby's categorization of "failure to understand students' level of understanding" as a failed humor attempt.

"I think when lecturers make very niche jokes, you've lost me at that point. Because if it's something that you find hilarious because you have a PhD in it, then go and joke about that with your lecturer friends. And making really niche jokes about specific people or a very specific scenario that you know a lot about, that perhaps an undergraduate wouldn't know, then you lose me at that point." (Victoria FG3)

Finally, participants acknowledged how lecturers' relative position of power to students impacts the reception of humor attempts. The positive findings from Scenario 1 and 6 demonstrated how these humor attempts could "improve the student-lecturer relationship, create a level of equality between students and lecturers" (FG2 and 3) or "break down the lecturer-student distance" (FG1), thus indicating the distance. Scenario 2, in particular, reinforced that lecturers' position of power makes mocking or banter inappropriate. For example, Kelly (FG2) noted how she would not appreciate any banter as "I don't have a very close relationship with most of my lecturers" and Victoria (FG3) thought that the "studentlecturer relationship is not necessarily strong enough to make a humorous comment like that and for it to land the way they expect."

\section{Conclusion}

This article analyses the literature on the benefits and risks of the use of humor in teaching and engages in further in-depth focus group analysis, therefore filling a gap in the literature by advancing a student-centered examination. 
The focus group data provided empirical support to existing literature by confirming that humor attempts can have both unintended and negative consequences, that education must precede subversion with humor, and the social conventions of a higher education institute and the unequal power dynamics of the student-lecturer relationship define what is 'appropriate'. Participants liked the idea of lecturers using humor because it can add variation to teaching, make the learning environment more comfortable, and help to develop rapport.

The focus groups also produced findings that advance the exiting literature. Participants noted their hope that lecturers 'reveal' part of their personality to make them more approachable rather than an impersonal deliverer of knowledge. However, lecturers who wish to reap the social and pedagogical benefits of using humor in their teaching should carefully consider the associated risks as perceived and articulated by undergraduate students:

1. The overuse of memes or silly analogies and references can reduce student's perception of teaching quality, waste lecture time, and make lecturers appear unprofessional.

2. Jokes have the potential to, even unintentionally, offend, be insensitive, or be exclusionary.

3. Joking about serious, sensitive, and controversial political issues is very difficult because it carries the risk of offending.

4. Making humor attempts at the expense of students is a high-risk strategy that could work, if an appropriate rapport is developed, but also carries the risk of discouraging other students from participating.

5. Overly personal self-depreciation that mocks appearance or life events can make students feel awkward or uncomfortable.

If lecturers were apprehensive about incorporating humor into their pedagogical approach, the focus groups noted that teaching with enthusiasm and using relatable examples were highly effective alternatives.

\section{References}

André, J. P. (2013). Opera and poison: A secret and enjoyable approach to teaching and learning chemistry. Journal of Chemical Education, 90(3), 352-357.

Appleby, D. (2018). Using humor in the college classroom: The pros and the cons.

Https://Www.Apa.Org. https://www.apa.org/ed/precollege/ptn/2018/02/humorcollege-classroom

Audritt, D. (2020). [Personal communication].

Baumgartner, J., \& Morris, J., S. (2006). The Daily Show Effect: Candidate Evaluations, Efficacy, and American Youth. American Politics Research, 34(3), 341-367.

Beavers, S. L. (2011). Getting Political Science in on the Joke: Using 'The Daily Show' and Other Comedy to Teach Politics. PS: Political Science \& Politics, 44(2).

Berk, R. A. (1996). Student ratings of 10 strategies for using humor in college teaching. Journal on Excellence in College Teaching, 7(3), 71-92.

Carter, J. (1989). Stand-up Comedy: The Book. Bantam Dell Publishing. 
Davis, J. R., \& Arend, B. (2013). Facilitating seven ways of learning: A resource for more purposeful, effective, and enjoyable college teaching. Stylus.

Englert, L. M. (2010). Learning with laughter: Using humor in the nursing classroom. Nursing Education Perspectives, 31(1), 48-49.

Fortson, S. B., \& Brown, W. E. (1998). Best and worst university instructors: The opinions of graduate students. College Student Journal, 32(4), 572-576.

Friedman, H. H., Friedman, L. W., \& Amoo, T. (2002). Using Humor in the Introductory Statistics Course. Journal of Statistics Education, 10(3).

Garner, R. L. (2006). Humor in Pedagogy: How Ha-Ha Can Lead to Aha! College Teaching, 54(1), 177-180.

Gillota, D. (2019). Reckless Talk: Exploration and Contradiction in Dave Chappelle's Recent Stand-Up Comedy. Studies in Popular Culture, 42(1), 1-22.

Gonçalves, I. S. (2010). Satire: A Double-edged Sword: A Study about the Impact of Political Satire. Cardiff University.

Goodboy, A. K., Booth-Butterfield, M., Bolkan, S., \& Griffin, D. J. (2015). The Role of Instructor Humor and Students' Educational Orientations inStudent Learning, Extra Effort, Participation, and Out-of-Class Communication. Communication Quarterly, 63(1), 44-61.

Granitz, N. A., Koernig, S. K., \& Harich, K. R. (2009). Now It's Personal: Antecedents and Outcomes of Rapport Between Business Faculty and Their Students. Journal of Marketing Education, 31(1), 52-65.

Hammer, R., Ronen, M., Sharon, A., Lankry, T., Huberman, Y., \& Zamtsov, V. (2010). Mobile Culture in College Lectures: Instructors' and Students' Perspectives. Interdisciplinary Journal of E-Learning and Learning Objects, 6(1), 293-304.

Hayes, N. (2016). Satire as an Educative Tool for Critical Pedagogy in the Public Affairs Classroom. Administrative Theory \& Praxis, 38(4), 251-266.

Hellman, S. V. (2007). Humor in the Classroom: STU'S Seven Simple Steps to Success. College Teaching, 55(1), 37-39.

Johnson, J. (2018). Top tips on how to make your lectures interesting. Times Higher Education (THE). https://www.timeshighereducation.com/features/top-tips-howmake-your-lectures-interesting

Kher, N., Molstad, S., \& Donahue, R. (1999). Using Humor in the College Classroom to Enhance Teaching Effectiveness in 'dread courses'. College Student Journal. https://www.semanticscholar.org/paper/Using-Humor-in-the-College-Classroom-toEnhance-in-Kher-Molstad/aa1c7cfeebd88514c0b4e8c77dc40a4699d3754a

Krefting, R. (2018). Savage New Media: Discursive Campaigns for/against Political Correctness. In J. Webber A. (Ed.), Joke Is on Us: Political Comedy in (Late) Neoliberal Times (pp. 221-244). Lexington Books.

Krueger, R. A., \& Casey, M. A. (2015). Focus Group Interviewing (5th ed.). Sage. MacMullan, T. (2007). Jon Stewart and the New Public Intellectual. In J. Holt (Ed.), The Daily Show and Philosophy: Moments of Zen in the Art of Fake News (pp. 57-68). Blackwell.

Meyer, J. C. (2000). Humor as a Double-Edged Sword: Four Functions of Humor in Communication. Communication Theory, 10(3), 310-331. 
Morreall, J. (2005). Humour and the Conduct of Politics. In S. Lockyer \& M. Pickering (Eds.), Beyond a Joke: The Limits of Humour (pp. 63-78). Palgrave Macmillan UK. https://doi.org/10.1057/9780230236776_4

Narula, D. R., Chaudhary, D. V., Agarwal, D. A., \& Narula, D. K. (2011). Humor as a Learning Aid in Medical Education. National Journal of Integrated Research in Medicine, 2, 4.

Nesi, H. (2012). Laughter in university lectures. Journal of English for Academic Purposes, 11(2), 79-89. https://doi.org/10.1016/j.jeap.2011.12.003

Özdoğru, A. A., \& McMorris, R. F. (2013). Humorous cartoons in college textbooks: Student perceptions and learning. Humor, 26(1), 135-154.

Powell, J. P., \& Andresen, L. W. (1985). Humour and teaching in higher education. Studies in Higher Education, 10(1), 79-90.

Rafiee, M., Kassaian, Z., \& Dastjerdi, H. V. (2010). The Application of Humorous Song in EFL Classrooms and Its Effects on Listening Comprehension. English Language Teaching, 3(4), 100-108.

Shally-Jensen, M., Jelen, T. G., \& Rozell, M. J. (2018). American political culture: An encyclopedia. ABC-CLIO.

Shatz, M., \& Helitzer, M. (2005). Comedy Writing Secrets (2nd Edition).

Tait, G., Lampert, J., Bahr, N., \& Bennett, P. (2015). Laughing with the lecturer: The use of humour in shaping university teaching. Journal of University Teaching \& Learning Practice, 12(3), 15.

Torosyan, R. (2007). Public Discourse and the Stewart Model of Critical Thinking. In J. Holt (Ed.), The Daily Show and Philosophy: Moments of Zen in the Art of Fake News (pp. 107-120). Blackwell.

Tregoning, J. (2018). Top tips on how to make your lectures interesting. Times Higher Education (THE). https://www.timeshighereducation.com/features/top-tips-howmake-your-lectures-interesting

Tsakona, V., \& Popa, D. E. (Eds.). (2011). Studies in political humour: In between political critique and public entertainment. John Benjamins Pub. Co.

Tsakona, V., \& Popa, D. E. (2013). Editorial: Confronting power with laughter. The European Journal of Humour Research, 1(2), 1-9.

Wanzer, M. B., \& Frymier, A. B. (1999). The relationship between student perceptions of instructor humor and student's reports of learning. Communication Education, 48(1), $48-62$.

Wilkinson, S. (1998). Focus group methodology: A review. International Journal of Social Research Methodology, 1(3), 181-203.

Worner, C. H., Romero, A., \& Bustamante, G. (2010). Achievement Evaluation within a NonConventional Framework: Some Experiences in Physics and Humour. Physics Education, 45(5), 539-543. 


\section{Appendix}

The six imaginary scenarios where hypothetical lecturers make "humor attempts" in their lecture and seminar situations, that were presented to focus group participants.

\section{Scenario 1}

\section{Lecturer persona}

Friendly and approachable

\section{Context}

At the beginning of the lecture, the lecturer tells a joke. The joke gets a small laugh from about half the audience.

\section{Humour attempt}

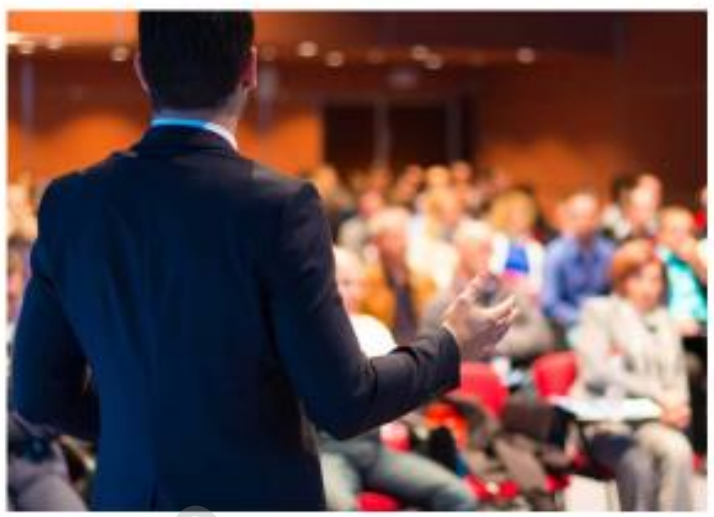

The joke is unrelated to the content of the lecture.

\section{Scenario 2}

\section{Lecturer persona}

\section{Serious}

\section{Context}

In the middle of a seminar, a student asks the lecturer a question. The lecturer responds to the question.

Humour attempt

The lecturer's response is relevant

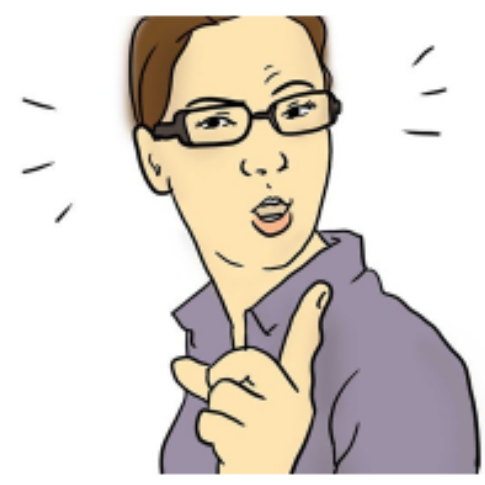
and humorous but targets the student with mockery/banter. 


\section{Scenario 3}

Lecturer persona

Mostly serious but also personable/friendly

\section{Context}

During a lecture with a supporting PowerPoint presentation.

The lecturer is serious while delivering the lecture but uses a "funny" meme or cartoon to illustrate the point

Humour attempt - A relevant meme

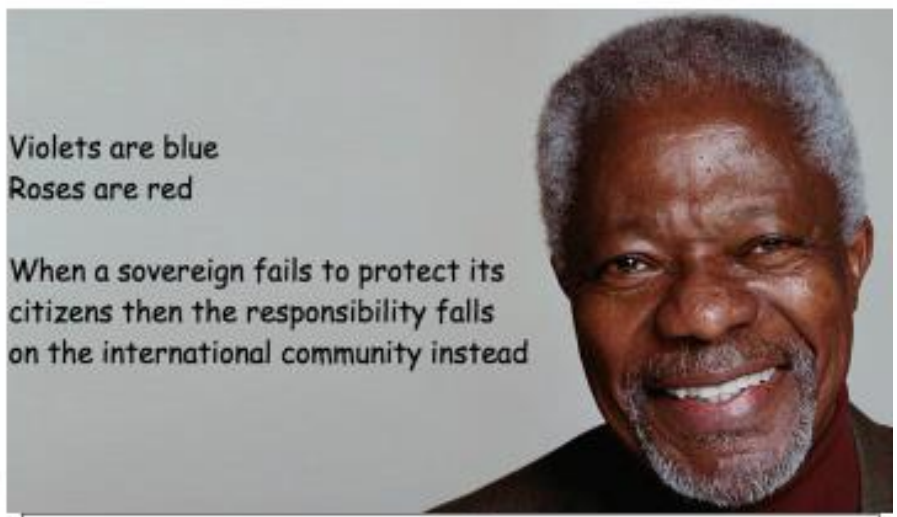

Humanitarian Intervention / Responsibility to Protect Kofi Annan: United Nations Secretary-General (1997-2006)

\section{Scenario 4}

\section{Lecturer persona}

Serious when lecturing but friendly in one to one situations

\section{Context}

During a lecture, the lecturer uses a 'pop culture' reference an as analogy or comparison to explain a concept. The comparison is made using humour.

\section{Humour attempt}

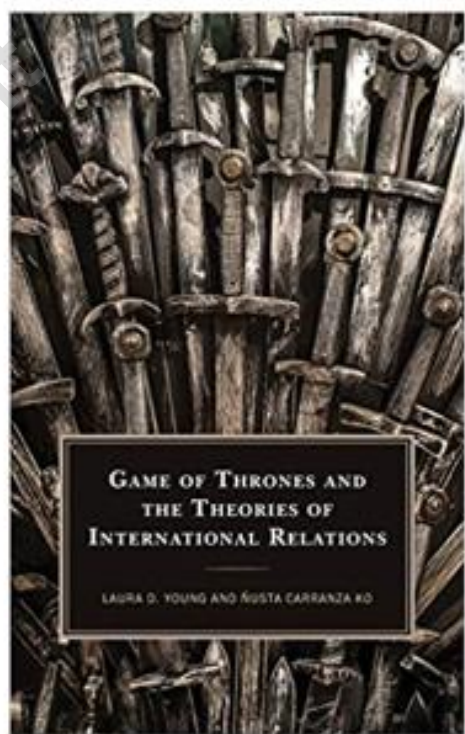

A pop culture reference 


\section{Scenario 5}

Lecturer persona

Serious and Funny

Context

Your lecturer delivers informative and well-researched lectures that

highlights key issues but supports the content with silly or comedic analysis, absurd analogy or comparisons or makes light of serious topics.

Humour attempt

Silly or comedic comparative analysis

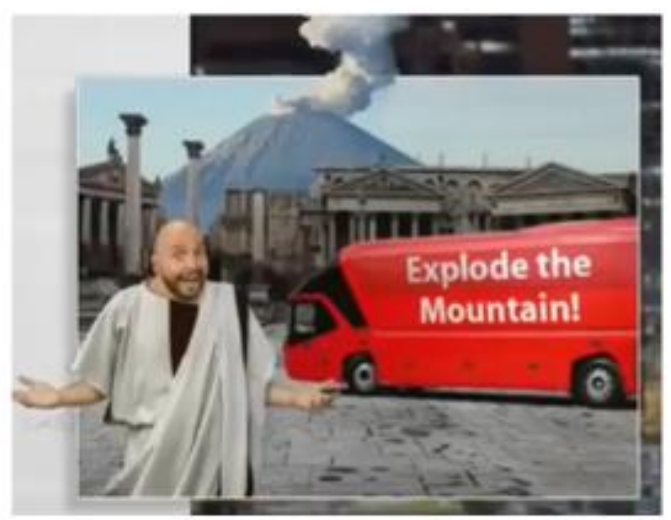

"Brexit is basically Pompeii, if the citizens voted for the Volcano"

\section{Scenario 6}

\section{Lecturer persona}

Mostly serious but often humorous through self-deprecation.

\section{Context}

Your lecturer delivers informative and well-researched lectures but does not take himself/herself too seriously and often pokes fun at themselves.

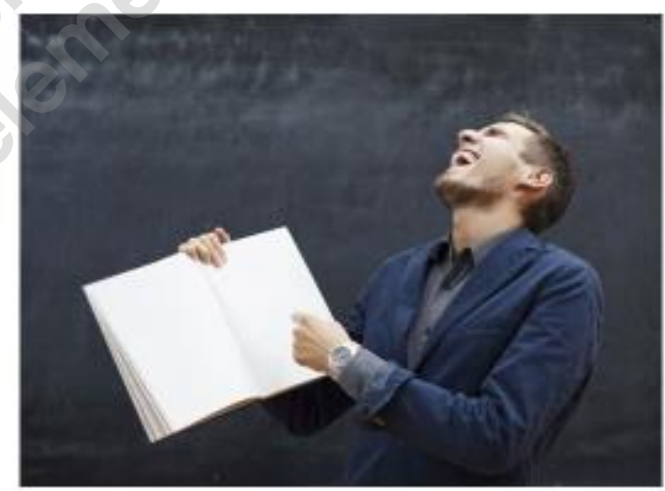

Humour attempt

Self-deprecating 